\title{
Corrigendum: Advances in non-dopaminergic pharmacological treatments of Parkinson's disease
}

\author{
Sandy Stayte ${ }^{1,2}$ and Bryce Vissel ${ }^{1,2 *}$ \\ ${ }^{1}$ Neuroscience, Neurodegenerative Disorders Laboratory, Garvan Institute of Medical Research, Sydney, NSW, Australia \\ 2 Faculty of Medicine, University of New South Wales, Sydney, NSW, Australia \\ *Correspondence: brycevissel@gmail.com
}

Edited and reviewed by:

Eero Vasar, University of Tartu, Estonia

Keywords: L-dopa, Parkinson's disease, animal models, dopamine, dyskinesias, gene therapy, neurodegeneration, therapeutics

\section{A Corrigendum on}

Advances in non-dopaminergic pharmacological treatments of Parkinson's disease

by Stayte, S., and Vissel, B. (2014). Front. Neurosci. 8:254. doi: 10.3389/fnins.2014. 00254

Figure 1 of the article by Stayte and Vissel (2014) contained an error during editing, which we now rectify. In the original Figure 1, the blue arrows representing the GABAergic projections to the LGP originate from the cerebral cortex. However, the blue arrows should be originating from the striatum. We include the updated version of Figure 1 with this correction.

\section{REFERENCES}

Stayte, S., and Vissel, B. (2014). Advances in nondopaminergic pharmacological treatments of Parkinson's disease. Front. Neurosci. 8:254. doi: 10. 3389/fnins.2014.00254

Conflict of Interest Statement: The authors declare that the research was conducted in the absence of any commercial or financial relationships that could be construed as a potential conflict of interest.
Received: 13 July 2014; accepted: 29 July 2014; published online: 19 August 2014.

Citation: Stayte S and Vissel B (2014) Corrigendum: Advances in non-dopaminergic pharmacological treatments of Parkinson's disease. Front. Neurosci. 8:254. doi: 10.3389/fnins.2014.00254

This article was submitted to Neuropharmacology, a section of the journal Frontiers in Neuroscience.

Copyright $\odot 2014$ Stayte and Vissel. This is an openaccess article distributed under the terms of the Creative Commons Attribution License (CC BY). The use, distribution or reproduction in other forums is permitted, provided the original author(s) or licensor are credited and that the original publication in this journal is cited, in accordance with accepted academic practice. No use, distribution or reproduction is permitted which does not comply with these terms. 

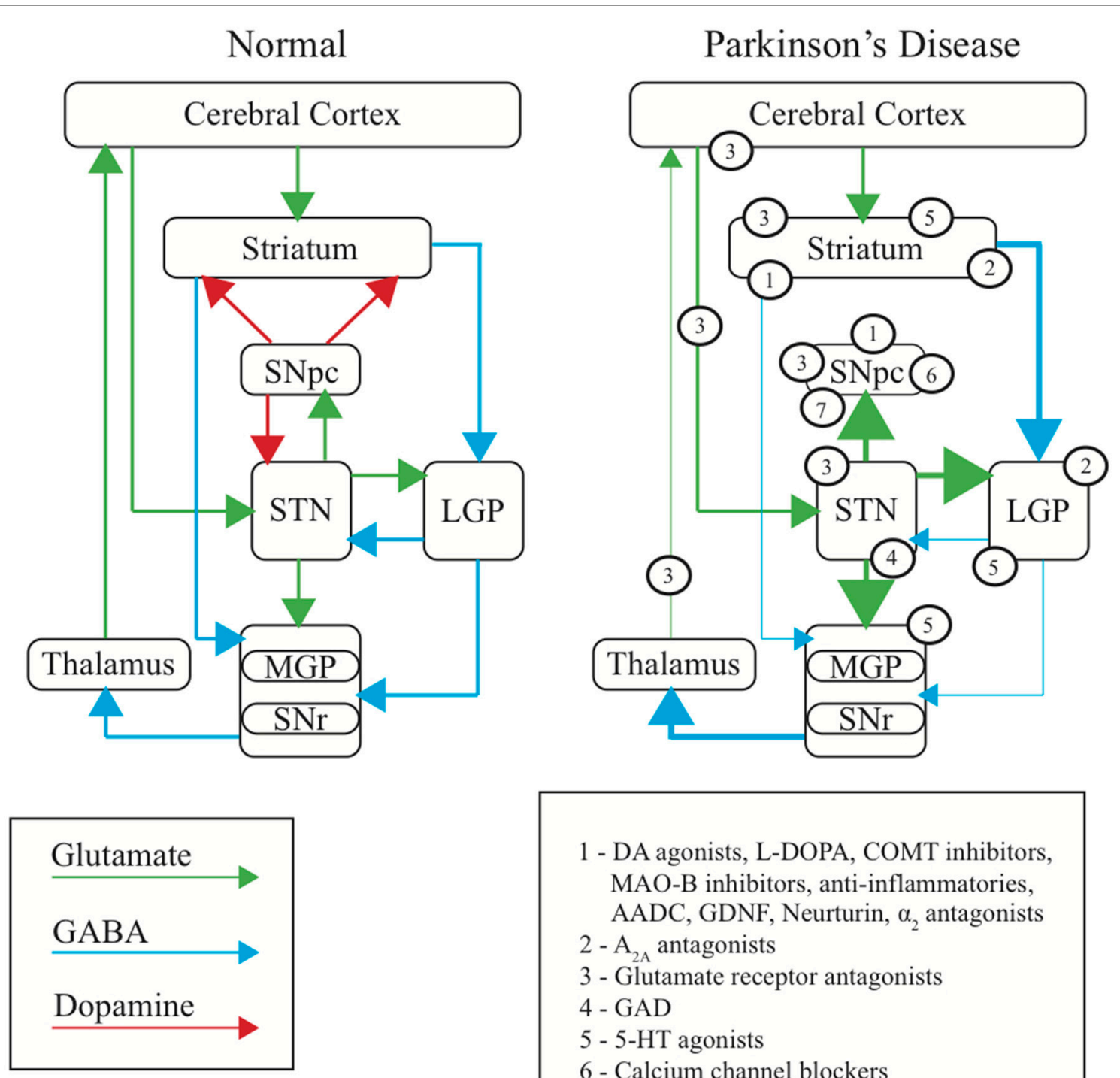

1 - DA agonists, L-DOPA, COMT inhibitors,

MAO-B inhibitors, anti-inflammatories,

AADC, GDNF, Neurturin, $\alpha_{2}$ antagonists

$2-\mathrm{A}_{2 \mathrm{~A}}$ antagonists

3 - Glutamate receptor antagonists

4 - GAD

5 - 5-HT agonists

6 - Calcium channel blockers

7 - Iron chelators

FIGURE 1 | Basal ganglia dysfunction in PD. Diagram representing the normal function of the basal ganglia (Left), the changes occurring in PD

(Right), and the site of primary action of therapeutic targets discussed in this review (numbered). Arrows represent the major neurotransmitters of glutamate (green), GABA (blue) and dopamine (red). Relative thickness of the arrows indicates level of activity of neurotransmitter. SNpc, substantia nigra pars compacta; SNr, substantia nigra reticulata; STN, subthalamic nucleus; MGP, medial globus pallidus; LGP, lateral globus pallidus. 